\title{
ELECTROLYTE AND WATER EXCRETIONS AND RENAL HEMO- DYNAMICS DURING INDUCED CONGESTION OF THE SUPERIOR AND INFERIOR VENA CAVA OF MAN ${ }^{1,2}$
}

\author{
By SAUL J. FARBER, WILLIAM H. BECKER, AND LUDWIG W. EICHNA \\ (From New York University College of Medicine and the Third [New York University] Medical \\ Division, Bellevue Hospital, New York, N. Y.)
}

(Submitted for publication May 26, 1953; accepted July 1, 1953)

It is apparent that the kidney is the organ ultimately responsible for the salt and water retention, hence the edema formation, in congestive heart failure, but why the kidney fails to excrete these substances normally in this disease state remains to be determined. Venous congestion, and renal venous congestion in particular, has been postulated as one of the factors playing a role in the decreased electrolyte and water excretions. Recent observations in animals and man lend support to this concept.

In dogs, each of the following acute procedures, designed to elevate renal or systemic venous pressure or both, has induced a decrease in the urinary excretion of electrolytes and water: partial ligation of the inferior vena cava above the renal veins (1), induced pericardial effusion (2) and partial ligation of one renal vein $(3,4)$, a procedure which induced the effect on the side of the increased renal venous pressure but not on the contralateral normal side. In chronic experiments, inferior vena caval congestion, including the renal veins, did not cause a sustained retention of electrolytes and water, whereas constriction of the inferior vena cava above the diaphragm, which added congestion of the liver, led to sustained edema and ascites $(1,5)$.

In man, induced venous congestion has necessarily been of short duration. The renal excretion of electrolytes and water has been shown to decrease during quiet standing (6), during acute abdominal compression of sufficient degree to raise inferior vena caval pressure (7), and in association

1 This study was assisted by Grants-in-Aid from the Life Insurance Medical Research Fund and the New York Heart Association, Inc.

2 Presented in part at the Forty-Third Annual Meeting of the American Society for Clinical Investigation, Atlantic City, N. J., April 30, 1951, and at the Twenty-Fifth Scientific Sessions of the American Heart Association, Cleveland, Ohio, April 19, 1952. with acute congestion of the extremities produced by inflating cuffs about the thighs and arms (8). The opposite effect, an increase in water and salt excretion, has been reported during venous congestion of the head of sitting subjects (9), during ace bandaging of the legs (10), and during the fall in systemic venous pressure which occurs in patients with congestive heart failure as a result of the intravenous administration of digoxin (11).

These considerations suggested a study, in man, of the renal excretion of electrolytes and water in response to congestion of the venous system, so produced that the kidney could be included in, or excluded from, the congested area. Accordingly, venous congestion was produced at various levels of the inferior vena cava and in the superior vena cava by means of an inflatable balloon on an indwelling intracardiac catheter (12) and the resultant renal effects were determined. The data indicate that acute congestion of a sizable segment of either vena cava in man provokes a reduction in the urinary excretion of electrolytes and water.

\section{METHODS AND PROCEDURES}

General. The plan of study was to determine several renal, urinary, and cardiovascular functions before, during, and after induced vena caval congestion. Renal plasma flow and glomerular filtration rate were determined by clearance methods, using para-aminohippurate and inulin respectively. The urinary excretions of sodium, potassium, and chloride were measured in successive periods, and the concentrations of these electrolytes in the blood were determined periodically. Arterial blood pressure was measured directly by Hamilton manometers and optical recording. Peripheral venous pressure in the congested area (femoral or antecubital vein) was determined by saline manometer. When technically possible, vena caval pressure, either distal or proximal to the balloon, was recorded through the intracardiac catheter by Hamilton manometer. Heart rate was counted from the electrocardiogram.

Subjects. Convalescing hospitalized patients without overt cardiac or renal disease served as subjects. Most of 
the subjects were in the older age group, hence arteriosclerosis and hypertension were frequently present. All patients received a regular hospital diet. Eight subjects, whose urinary sodium excretions were low, were given 6 to 8 grams of salt orally the day before the study, in order to assure a more adequate urinary excretion of sodium. No extra fluids were given immediately before or during the observations.

Procedures. The observations were made in the morning in the post-absorptive state and the following procedures were carried out routinely. An electrocardiogram was taken and an indwelling catheter was placed in the urinary bladder. After the injection of appropriate priming doses, a sustaining infusion of inulin and para-aminohippurate in distilled water was delivered continuously by a Bowman pump at a rate of $1 \mathrm{ml}$. per min. A "balloon" intracardiac catheter was placed in the desired location in the vena cava (12) and its distal lumen was perfused continuously with a slow drip of 5 per cent dextrose in water. A gauge No. 18 needle was inserted into the femoral or antecubital vein, attached to a saline manometer and intermittently flushed with small amounts of 0.9 per cent saline solution. The femoral artery was cannulated with an indwelling Cournand needle. Heparin, 50 to 75 mg. per L., was added to all infusions except that delivered by the pump. A 2 per cent solution of metycaine was used for local anesthesia.

Determinations were made in successive periods, each of 10 to 15 minutes duration. Arterial and vena caval pressures and the electrocardiogram were recorded at the mid-point of each period, while water and electrolyte excretions and renal hemodynamics were determined as averages for the period. All blood samples were of arterial blood and obtained at the mid-point of each period. Peripheral venous pressure in the congested area was read continuously at approximately two minute intervals. The zero point of reference for all pressure measurements was 5.5 to $6.5 \mathrm{~cm}$. posterior to the angle of Louis.

After two to four control periods, the balloon was inflated slowly (over 6 to 10 minutes) with 20 per cent diodrast solution, injected at a rate of 0.5 to $1.0 \mathrm{ml}$. per min. until the distal venous pressure was raised to 150 $\mathrm{mm}$. to $220 \mathrm{~mm}$. saline. Then followed two to four periods during which the balloon was kept inflated and the distal venous pressure elevated. Thereafter, the balloon was deflated; the distal venous pressure fell promptly, and three to four additional periods of determinations were made. While the balloon was inflated its position was checked repeatedly by fluoroscopy to assure that it remained in the desired location: for the inferior vena cava above the renal veins, at or above the mid-point of the hepatic shadow and often just under the diaphragm; for the inferior vena cava below the renal veins, at or just above the iliac crests; for the superior vena cava, in the mid or lower third of the cava.

Analyses. Standard chemical methods were used for the determination of the blood and urine concentrations of inulin $(13,14)$, para-aminohippurate (15), and chloride (16). Sodium and potassium concentrations were determined by an internal standard flame photometer. Plasma, separated from erythrocytes within 15 minutes of sampling, was used for the determination of the above substances in blood except for sodium, which was determined in serum. Dry heparin was the anticoagulant. Hematocrits were obtained on arterial blood centrifuged in Wintrobe tubes. Plasma protein concentrations were derived from specific gravity measurements made by the copper sulfate technique (17). Systolic and diastolic arterial pressures were obtained by averaging the respective pressures over two respiratory cycles; mean arterial pressure and mean vena caval pressure were determined by planimetric integration of these two pressure waves over the same two respirations. The average of the saline manometer readings during a period was taken as the representative peripheral venous pressure for the period.

\section{EFFECTS OF CONGESTION OF INFERIOR VENA CAVA}

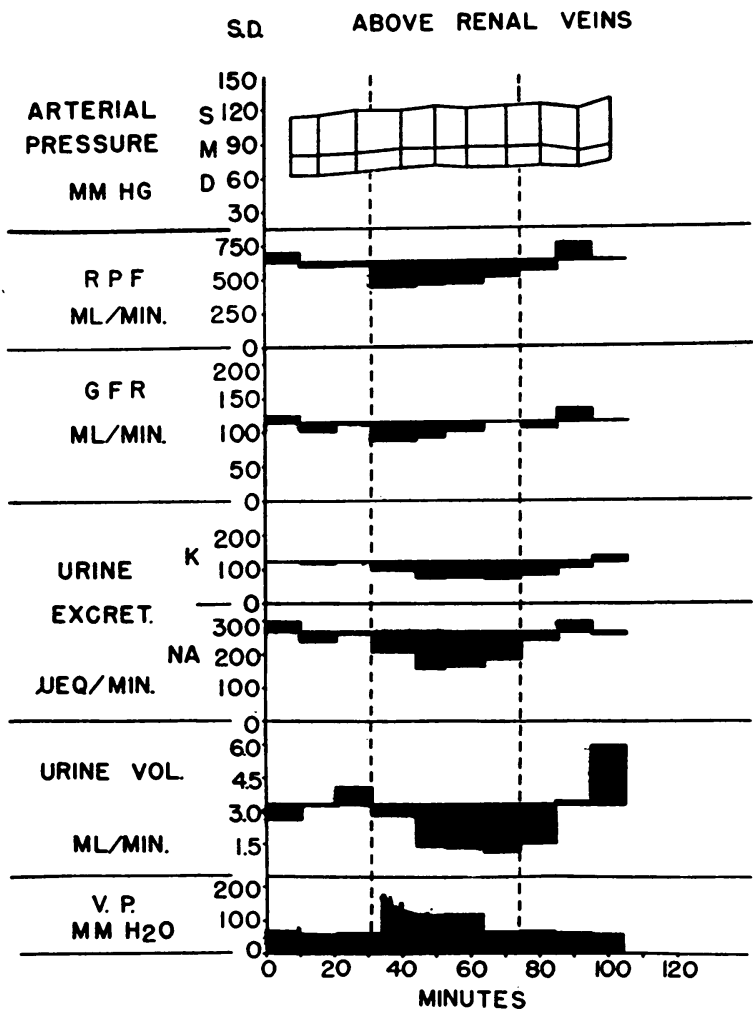

Fig. 1. The Effects of Inferior Vena Caval Congestion, Including the Renal Veins; a Typical RESPONSE

The dotted line on the left indicates inflation of balloon in the inferior vena cava above the renal veins, the dotted line on the right, deflation of the balloon.

Systemic arterial pressures and peripheral venous pressures are plotted as determined values above zero; water and electrolyte excretions, glomerular filtration rates and renal plasma flows are plotted, for each period, as changes from the average of their respective three control determinations. 


\section{RESULTS}

With few exceptions, the subjects tolerated satisfactorily the confining and tedious three to four hour study. While the balloon was inflated they were unaware of anything unusual, offered no complaints, and showed no evidence of circulatory distress. This benign state was attributed to the slow inflation of the balloon and to keeping the elevated distal venous pressure under $250 \mathrm{~mm}$. saline. In several initial observations, impending syncope resulted when the balloon was inflated too rapidly and the distal venous pressure was raised to higher levels. The data of these observations have been excluded from this report.

The pattern of the changes produced by vena caval congestion was largely the same whether the increase in venous pressure involved the inferior vena cava including the renal veins (Figure 1 ), the

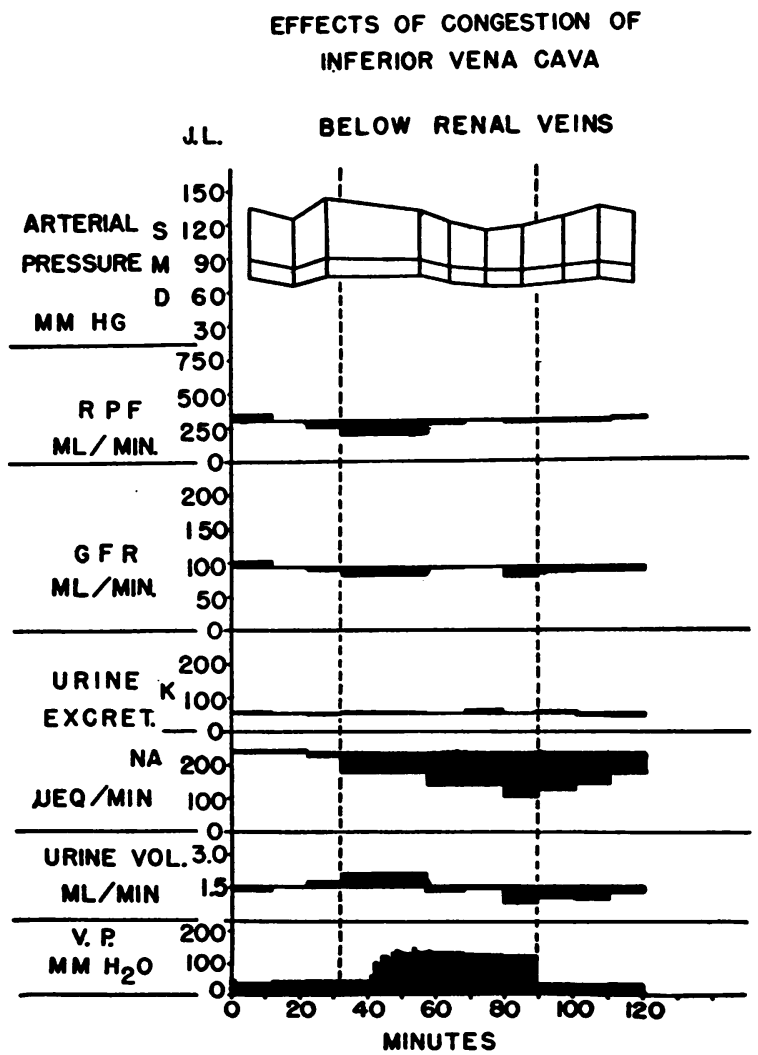

Fig. 2. The Effects of Inferior Vena Cafal Congestion below the Renal. VeINS; a Typical Response

The dotted line on the left indicates inflation of balloon in the inferior vena cava below the renal veins, the dotted line on the right, deflation of the balloon.

For details of plotting see Figure 1.

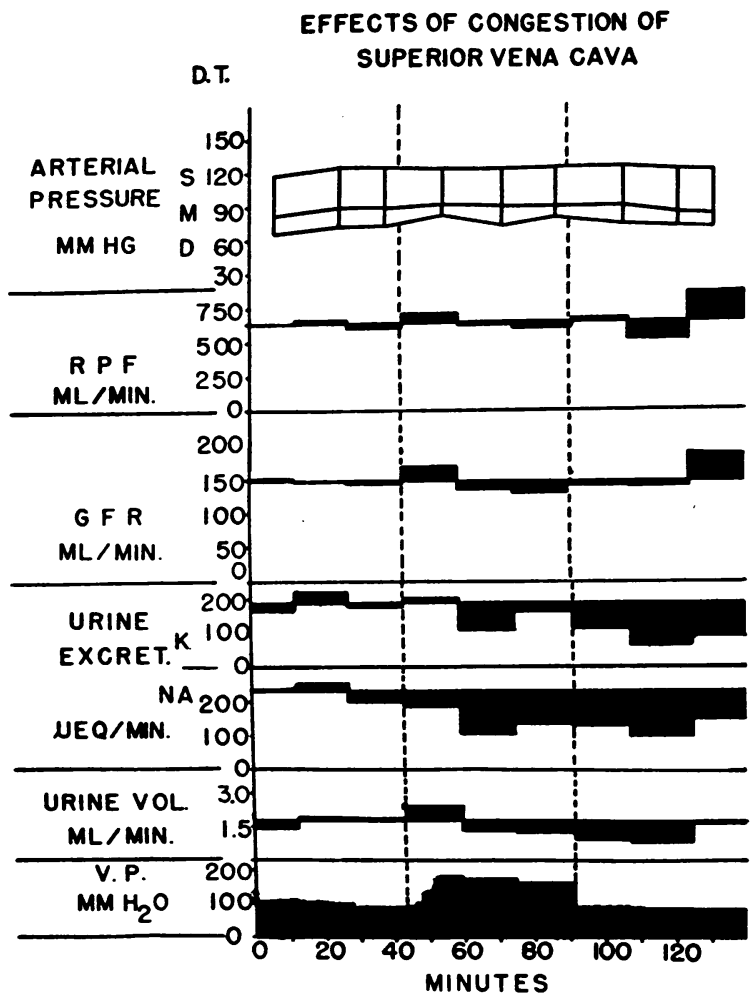

Fig. 3. The Efrects of Superior Vena Catal Congestion; a Typical Response

The left dotted line indicates inflation of balloon in lower third of the superior vena cava, the right dotted line, deflation of the balloon.

For details of plotting see Figure 1.

inferior vena cava below the renal veins (Figure 2 ), or the superior vena cava (Figure 3 ). For this reason, the effects of congestion of one area only, that produced by inflating the balloon in the inferior vena cava above the renal veins, will be described in detail. It is to be understood that the effects of congestion of the other two areas were similar, except for the specific differences which will be presented.

Tables I to VIII present the data and their statistical analysis by the method of the critical ratio ( $t$ test). The analysis was made for each control, inflation, and post-deflation period for each function measured. For each period only the data for the subjects represented in that period were used and the values for each individual were always analyzed with respect to the average of his control period values. Hereafter, the words "significant" will be used only where the $P$ value is 0.01 or less, "probably significant" where the $P$ 


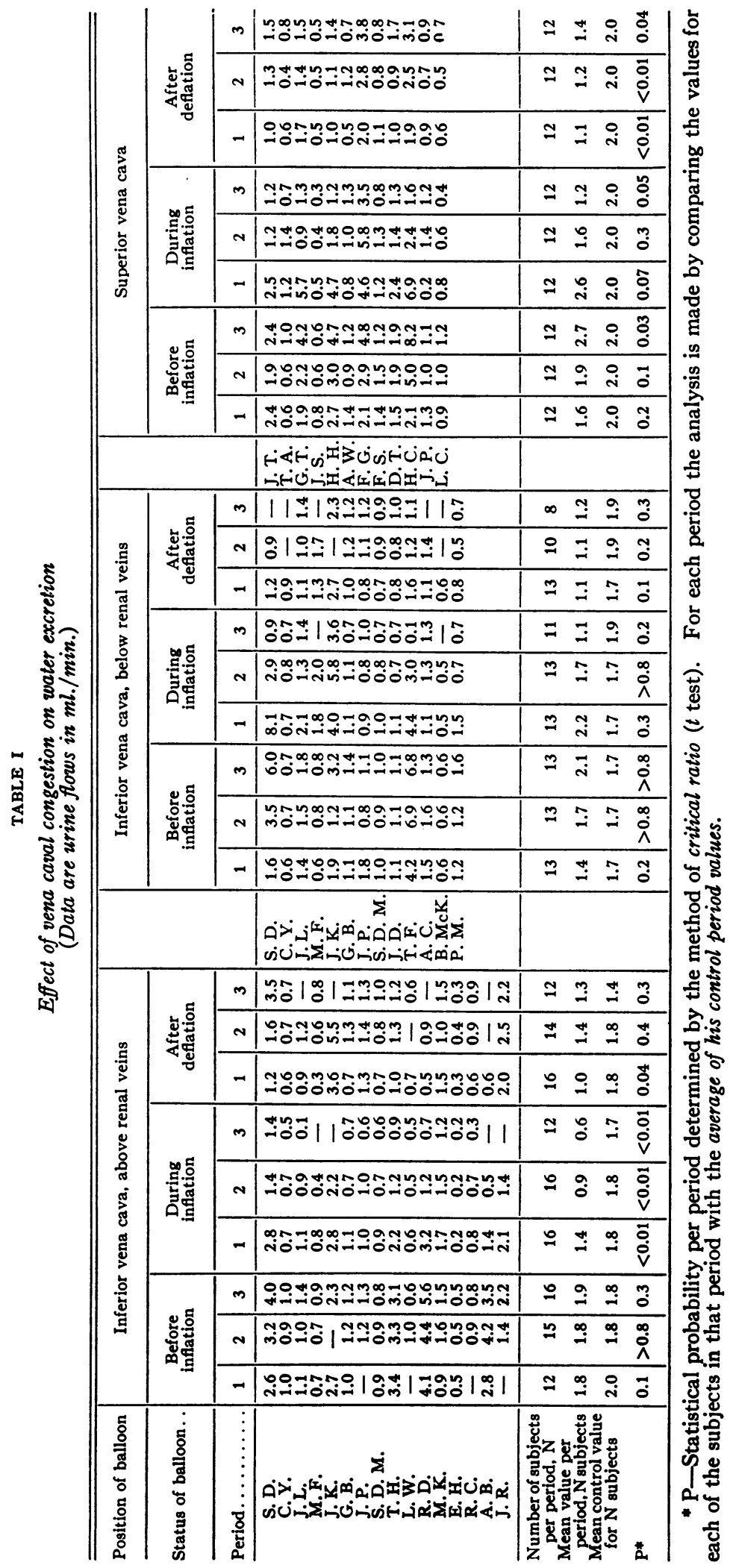




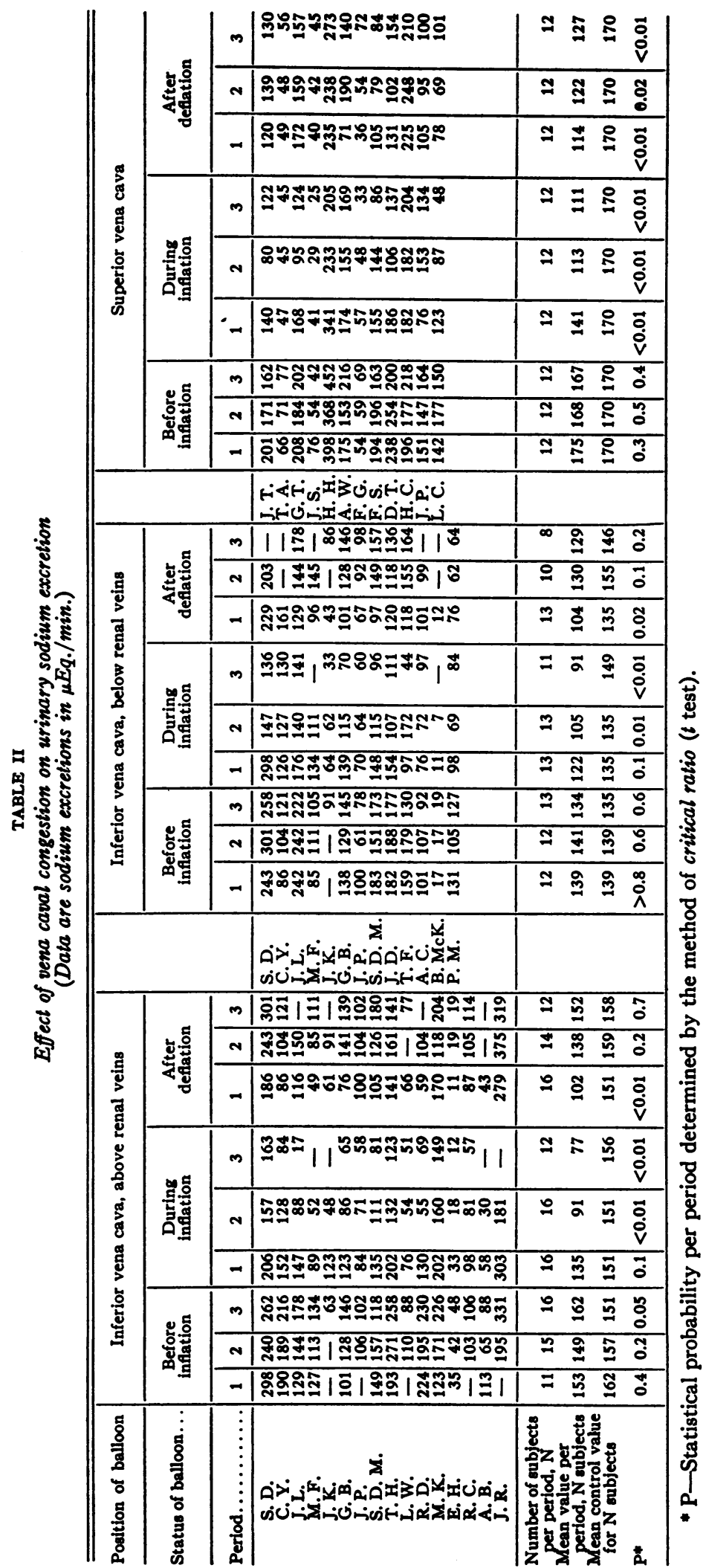


TABLE III

Effect of vena caval congestion on urinary potassium excretion

(The data are averaged potassium excretions in $\mu E q . /$ min. for number of subjects indicated)

\begin{tabular}{|c|c|c|c|c|c|c|c|c|c|}
\hline \multirow{3}{*}{$\begin{array}{l}\text { Position of balloon } \ldots \ldots \ldots \ldots \ldots \ldots \\
\text { Status of balloon } \ldots \ldots \ldots \ldots \ldots \ldots \ldots \\
\text { Period } \ldots \ldots \ldots \ldots \ldots \ldots \ldots \ldots \ldots \ldots \ldots \ldots \ldots \ldots\end{array}$} & \multicolumn{9}{|c|}{ Inferior vena cava, above renal veins } \\
\hline & \multicolumn{3}{|c|}{ Before inflation } & \multicolumn{3}{|c|}{ During inflation } & \multicolumn{3}{|c|}{ After deflation } \\
\hline & 1 & 2 & 3 & 1 & 2 & 3 & 1 & 2 & 3 \\
\hline \multirow{3}{*}{$\begin{array}{l}\text { Number of subjects per } \\
\text { period, N } \\
\text { Mean value per period, } \\
\text { N subjects } \\
\text { Mean control value for } \\
\text { N subjects }\end{array}$} & 11 & 15 & 16 & 16 & 16 & 12 & 16 & 14 & 12 \\
\hline & 66 & 58 & 57 & 52 & 42 & 42 & 54 & 61 & 52 \\
\hline & 64 & 59 & 58 & 58 & 58 & 60 & 58 & 55 & 53 \\
\hline $\mathrm{P}^{*}$ & 0.4 & 0.4 & 0.5 & 0.2 & $<0.01$ & $<0.01$ & 0.4 & $>0.8$ & 0.8 \\
\hline \multirow{4}{*}{$\begin{array}{l}\text { Position of balloon.......... } \\
\text { Number of subjects per } \\
\text { period, N } \\
\text { Mean value per period, } \\
\text { N subjects } \\
\text { Mean control value for } \\
\text { N subjects }\end{array}$} & \multicolumn{9}{|c|}{ Inferior vena cava, below renal veins } \\
\hline & 11 & 11 & 13 & 13 & 13 & 11 & 13 & 10 & \\
\hline & 59 & 58 & 54 & 52 & 50 & 42 & 53 & 52 & 54 \\
\hline & 58 & 58 & 55 & 55 & 55 & 56 & 55 & 56 & 56 \\
\hline $\mathbf{P}^{*}$ & 0.7 & $>0.8$ & $>0.8$ & 0.3 & 0.3 & 0.02 & 0.7 & 0.6 & 0.6 \\
\hline \multirow{4}{*}{$\begin{array}{l}\text { Position of balloon......... } \\
\text { Number of subjects per } \\
\text { period, N } \\
\text { Mean value per period, } \\
\text { N subjects } \\
\text { Mean control value for } \\
\text { N subjects }\end{array}$} & \multicolumn{9}{|c|}{ Superior vena cava } \\
\hline & 12 & 12 & 12 & 12 & 12 & 12 & 12 & 12 & 12 \\
\hline & 81 & 90 & 96 & 85 & 73 & 70 & 69 & 63 & 63 \\
\hline & 88 & 88 & 88 & 88 & 88 & 88 & 88 & 88 & 88 \\
\hline $\mathrm{P}^{*}$ & 0.05 & 0.5 & 0.08 & 0.4 & $<0.01$ & $<0.01$ & $<0.01$ & 0.02 & $<0.01$ \\
\hline
\end{tabular}

* P-Statistical probability per period determined by the method of critical ratio ( $t$ test).

value is 0.02 or 0.03 , and "possibly significant" for $P$ values of 0.04 and 0.05 .

\section{Effects of inflation of the balloon in the inferior vena cava above the renal veins}

Water excretion (Table $I$ ). During the venous congestion, urine flow decreased in all 16 subjects, moderately to markedly in 13 , slightly in two, equivocally in one. This effect occurred at varying rates of control urine excretion between $0.5 \mathrm{ml}$. per min. (E. H.) and $4.7 \mathrm{ml}$. per min. (R. D.). The decrease was usually progressive, and after the first period of congestion urine flow was significantly less than the control excretion. Following deflation of the balloon, urine flow increased in all subjects, and 30 minutes later reached control levels in 11 of the 16 subjects. Twenty to thirty minutes after the deflation the flow rates were not significantly different from control values.

Albuminuria did not occur, either during the venous congestion or after its release.
Sodium excretion (Table II). Sodium excretion decreased moderately to markedly in all 16 subjects. Again the effect was usually progressive, and after the tenth minute of congestion, sodium excretion fell significantly below control values. The decrease occurred at both low and high levels of control excretion; thus, from $42 \mu \mathrm{Eq}$. per min. to $12 \mu \mathrm{Eq}$. per min. in E. H. and from $267 \mu \mathrm{Eq}$. per $\min$. to $163 \mu \mathrm{Eq}$. per min. in S. D. Following deflation of the balloon the excretion rate rose in all subjects. During the first post-deflation period the rate was still significantly reduced, but thereafter sodium excretion was not significantly different from control values.

Potassium excretion (Table III). Potassium excretion decreased less consistently than did water or sodium excretion. The decreases tended to be less progressive and apparently greater at the higher levels (R. D., $124 \mu \mathrm{Eq}$. per min. to $80 \mu \mathrm{Eq}$. per min.) than the lower levels (R. C., $19 \mu \mathrm{Eq}$. per min. to $16 \mu \mathrm{Eq}$. per min.) of control excretion. Nevertheless, for the group, potassium excretion 
was significantly reduced during the second and third periods of congestion. After release of congestion the excretion rates returned promptly to control levels.

Chloride excretion (Table IV). Chloride excretion decreased in a manner similar to sodium excretion. Moderate to marked falls occurred at both high (S. D., $330 \mu \mathrm{Eq}$. per min. to $203 \mu \mathrm{Eq}$. per min.) and low (T. H., $24 \mu \mathrm{Eq}$. per min. to 15 $\mu \mathrm{Eq}$. per min.) levels of control excretion in 15 of the 16 subjects, and the mean excretion rate was significantly reduced during the second and third periods of congestion. With release of congestion, chloride excretion usually increased promptly but still remained significantly reduced during the first post-deflation period, after which control values were reached.

Renal plasma flow (Table $V$ ). Probably due to advanced age of the subjects and the coexistence of hypertension and arteriosclerosis, the mean control renal plasma flow was low (348 ml. per min.). A variable decrease in flow, averaging 20 to 30 per cent, occurred during at least one of the periods of congestion in each of the eight subjects studied. As the venous congestion was maintained, the flow rates varied and did not change progressively as in the case of the electrolyte excretions. For the group, renal plasma flow was significantly decreased during the second period of congestion and probably significantly reduced during the third. Following deflation of the balloon, renal plasma flow returned promptly to control values.

Glomerular filtration rate (Table VI). The mean control filtration rate was somewhat reduced (90 ml. per min.), again probably a function of the type of subjects. A variable (10 to 25 per cent), usually small, decrease in filtration rate occurred during the first two periods of congestion in all eight subjects studied and at both normal (R. D., $133 \mathrm{ml}$. per min. to $82 \mathrm{ml}$. per min.) and impaired (M. K., $44 \mathrm{ml}$. per min. to $34 \mathrm{ml}$. per min.) filtration rates. In the third congestion period, filtration rate rose in five subjects and in three reached control levels, but the mean value for the

TABLE IV

Effect of vena caval congestion on urinary chloride excretion

(The data are averaged chloride excretions in $\mu E q . /$ min. for number of subjects indicated)

\begin{tabular}{|c|c|c|c|c|c|c|c|c|c|}
\hline \multirow{3}{*}{$\begin{array}{l}\text { Position of balloon } \ldots \ldots \ldots \ldots \ldots \ldots \ldots \\
\text { Status of balloon } \ldots \ldots \ldots \ldots \ldots \ldots \ldots \ldots \\
\text { Period } \ldots \ldots \ldots \ldots \ldots \ldots \ldots \ldots \ldots \ldots\end{array}$} & \multicolumn{9}{|c|}{ Inferior vena cava, above renal veins } \\
\hline & \multicolumn{3}{|c|}{ Before inflation } & \multicolumn{3}{|c|}{ During inflation } & \multicolumn{3}{|c|}{ After deflation } \\
\hline & . 1 & 2 & 3 & 1 & 2 & 3 & 1 & 2 & 3 \\
\hline \multirow{3}{*}{$\begin{array}{l}\text { Number of subjects per } \\
\text { period, } N \\
\text { Mean value per period, } \\
\text { N subjects } \\
\text { Mean control value for } \\
\text { N subjects }\end{array}$} & 12 & 15 & 16 & 16 & 16 & 12 & 16 & 14 & 12 \\
\hline & 150 & 152 & 164 & 151 & 101 & 94 & 117 & 146 & 158 \\
\hline & 154 & 160 & 154 & 154 & 154 & 149 & 154 & 158 & 159 \\
\hline$P^{*}$ & 0.6 & 0.2 & 0.1 & 0.7 & $<0.01$ & $<0.01$ & $<0.01$ & 0.4 & $>0.8$ \\
\hline \multirow{4}{*}{$\begin{array}{l}\text { Position of balloon......... } \\
\text { Number of subjects per } \\
\text { period, N } \\
\text { Mean value per period, } \\
\text { N subjects } \\
\text { Mean control value for } \\
\text { N subjects }\end{array}$} & \multicolumn{9}{|c|}{ Inferior vena cava, below renal veins } \\
\hline & 13 & 13 & 13 & 13 & 13 & 11 & 13 & 10 & 8 \\
\hline & 168 & 153 & 154 & 157 & 131 & 106 & 121 & 156 & 156 \\
\hline & 158 & 158 & 158 & 158 & 158 & 166 & 158 & 171 & 169 \\
\hline$P^{*}$ & 0.3 & 0.5 & 0.3 & $>0.8$ & 0.02 & $<0.01$ & $<0.01$ & 0.2 & 0.2 \\
\hline \multirow{4}{*}{$\begin{array}{l}\text { Position of balloon.......... } \\
\text { Number of subjects per } \\
\text { period, } N \\
\text { Mean value per period, } \\
\text { N subjects } \\
\text { Mean control value for } \\
\text { N subjects }\end{array}$} & \multicolumn{9}{|c|}{ Superior vena cava } \\
\hline & 12 & 12 & 12 & 12 & 12 & 12 & 12 & 12 & 12 \\
\hline & 199 & 195 & 222 & 166 & 124 & 130 & 134 & 136 & 140 \\
\hline & 202 & 202 & 202 & 202 & 202 & 202 & 202 & 202 & 202 \\
\hline $\mathbf{P}^{*}$ & 0.7 & 0.4 & 0.06 & $<0.01$ & $<0.01$ & $<0.01$ & $<0.01$ & 0.02 & 0.02 \\
\hline
\end{tabular}

* P-Statistical probability per period determined by the method of critical ratio ( $t$ test). 


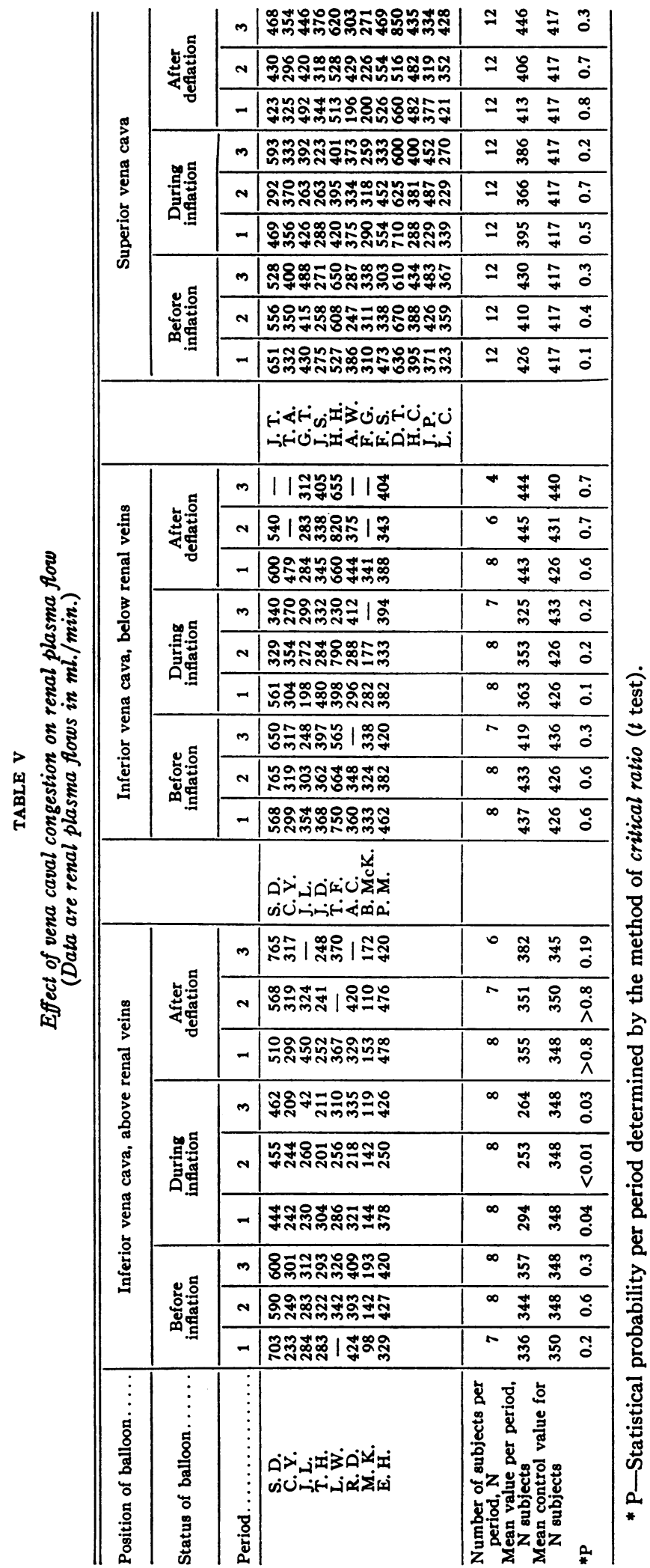




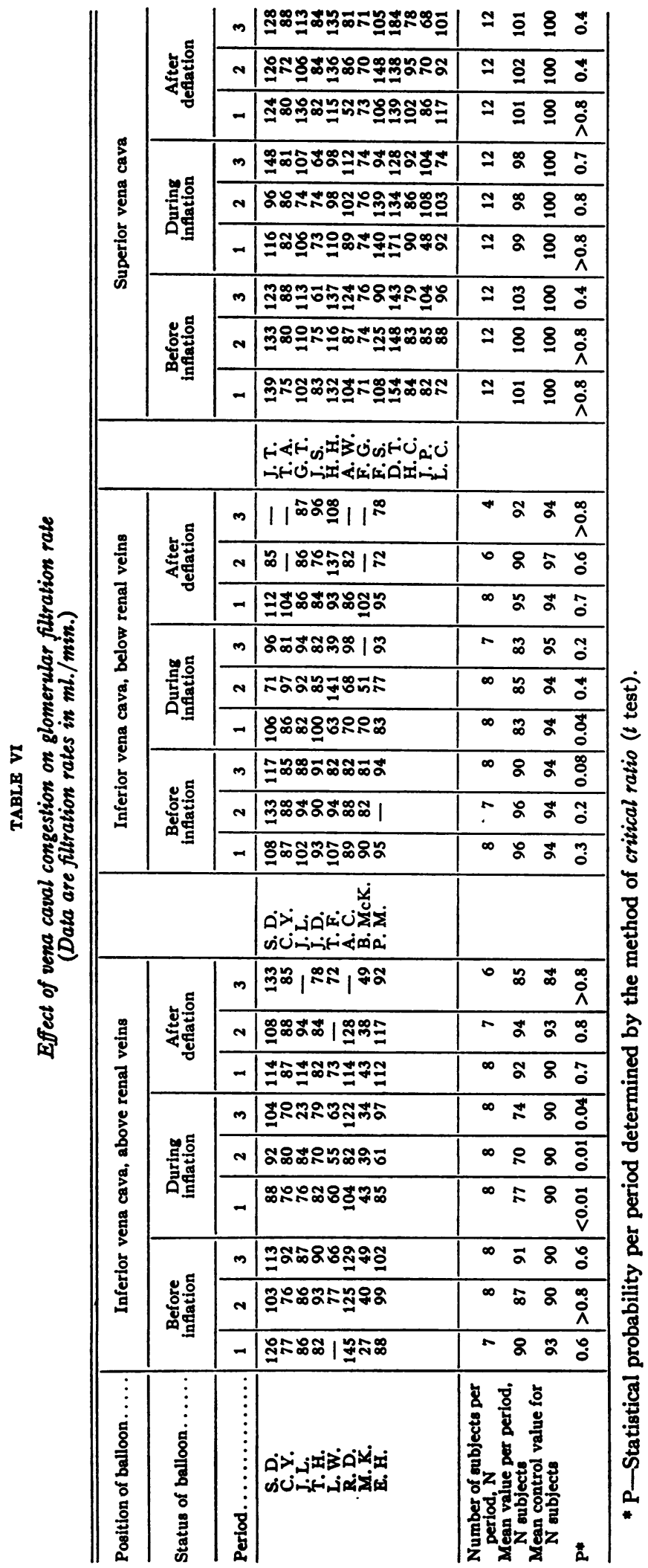


TABLE VII

Effect of vena caval congestion on systemic arterial blood pressures* (The data are averaged blood pressures in $\mathrm{mm}$. Hg per period for number of subjects indicated)

\begin{tabular}{|c|c|c|c|c|c|c|c|c|c|}
\hline \multirow{3}{*}{$\begin{array}{l}\text { Position of balloon } \ldots \ldots \ldots \ldots \ldots \ldots \\
\text { Status of balloon } \ldots \ldots \ldots \ldots \ldots \ldots \ldots \\
\text { Period } \ldots \ldots \ldots \ldots \ldots \ldots \ldots \ldots \ldots\end{array}$} & \multicolumn{3}{|c|}{$\begin{array}{l}\text { Inferior vena cava } \\
\text { above renal veins }\end{array}$} & \multirow{2}{*}{\multicolumn{3}{|c|}{$\begin{array}{c}\begin{array}{c}\text { Inferior vena cava } \\
\text { below renal veins }\end{array} \\
\text { During inflation }\end{array}$}} & \multirow{2}{*}{\multicolumn{3}{|c|}{$\begin{array}{c}\text { Superior vena cava } \\
\text { During inflation }\end{array}$}} \\
\hline & \multicolumn{3}{|c|}{ During inflation } & & & & & & \\
\hline & 1 & 2 & 3 & 1 & 2 & 3 & 1 & 2 & 3 \\
\hline Number of subjects per period, $\mathrm{N} . \ldots \ldots$ & 8 & 9 & 9 & 8 & 8 & 8 & 12 & 12 & 11 \\
\hline \multicolumn{10}{|c|}{ Systolic blood pressure } \\
\hline \multirow{2}{*}{$\begin{array}{l}\text { Mean value per period, } \\
\text { N subjects } \\
\text { Mean control value for } \\
\text { N subjects }\end{array}$} & 153 & 143 & 145 & 141 & 139 & 138 & 142 & 142 & 139 \\
\hline & 155 & 152 & 152 & 149 & 149 & 148 & 147 & 147 & 146 \\
\hline $\mathrm{P} \dagger$ & 0.7 & 0.1 & 0.4 & $<0.01$ & 0.08 & 0.03 & 0.02 & 0.3 & 0.05 \\
\hline \multicolumn{10}{|c|}{ Diastolic blood pressure } \\
\hline \multirow{2}{*}{$\begin{array}{l}\text { Mean value per period, } \\
\text { N subjects } \\
\text { Mean control value for } \\
\text { N subjects }\end{array}$} & 78 & 74 & 76 & 74 & 72 & 73 & 76 & 76 & 76 \\
\hline & 76 & 75 & 75 & 73 & 73 & 73 & 75 & 75 & 76 \\
\hline $\mathrm{P} \dagger$ & 0.3 & $>0.8$ & $>0.8$ & 0.6 & 0.6 & - & 0.2 & 0.2 & - \\
\hline \multicolumn{10}{|c|}{ Mean blood pressure } \\
\hline \multirow{2}{*}{$\begin{array}{l}\text { Mean value per period, } \\
\text { N subjects } \\
\text { Mean control value for } \\
\text { N subjects }\end{array}$} & 96 & 94 & 91 & 91 & 89 & 90 & 97 & 100 & 97 \\
\hline & 96 & 95 & 95 & 93 & 93 & 93 & 99 & 99 & 99 \\
\hline $\mathrm{Pt}$ & 一 & $>0.8$ & 0.2 & 0.05 & 0.2 & 0.3 & 0.06 & 0.7 & 0.02 \\
\hline \multicolumn{10}{|c|}{ Pulse pressure } \\
\hline $\begin{array}{l}\text { N subjects } \\
\text { Mean control value for }\end{array}$ & 75 & 70 & 71 & 68 & 66 & 64 & 66 & 66 & 63 \\
\hline N subjects & 80 & 79 & 79 & 76 & 76 & 75 & 72 & 72 & 70 \\
\hline $\mathrm{P} \dagger$ & 0.1 & 0.04 & 0.2 & $<0.01$ & 0.02 & 0.02 & $<0.01$ & $<0.01$ & 0.01 \\
\hline
\end{tabular}

* The variations in arterial pressures from period to period in each subject were small, therefore the individual data have been omitted. The data for the 3 before inflation and 3 after deflation periods have been omitted, since in no instance did the value in any of these periods differ significantly from the average of the control period values. $\dagger \mathrm{P}$-Statistical probability per period determined by the method of critical ratio ( $t$ test).

group was still decreased. Statistically, the decreases during the first and second periods of congestion were significant and during the third period possibly significant. Upon deflation of the balloon, filtration rates promptly rose to control levels.

Filtration fraction changed but little and not significantly. The average of the control values was 0.25 . The mean values were $0.26,0.28$, and 0.24 respectively, for the three periods of venous congestion, and $0.26,0.26$, and 0.24 for the three successive post-deflation periods.

Arterial blood pressure (Table VII). In individual subjects the changes in arterial pressure varied from a fall (E. H., $149 / 60$ to $118 / 52 \mathrm{~mm}$. $\mathrm{Hg}$ ) to no change (S. D., $116 / 63$ to $121 / 68 \mathrm{~mm}$. $\mathrm{Hg}$ ) to a rise (R. D., $196 / 91$ to $216 / 116 \mathrm{~mm}$. $\mathrm{Hg}$ ).
Whatever the change, it was almost always small. The group response consisted of a slight fall ( -7 to $-9 \mathrm{~mm} . \mathrm{Hg}$ ) in systolic pressure with no change or a slight rise $(-1$ to $+2 \mathrm{~mm}$. $\mathrm{Hg})$ in diastolic pressure. As a result, pulse pressure usually narrowed slightly ( -5 to $-9 \mathrm{~mm}$. $\mathrm{Hg}$ ) while mean pressure remained unchanged or fell slightly $(-1$ to $-4 \mathrm{~mm}$. $\mathrm{Hg})$. Only the fall in pulse pressure in the second inflation period approached a significant change $(P=0.04)$.

Neither the heart rate (Table VIII) nor the electrocardiogram changed significantly at any time.

The arterial hematocrit and plasma protein concentration remained unchanged during and after the venous congestion, hence significant hemoconcentration probably did not occur. 


\section{Effects of inflation of the balloon in the in- ferior vena cava below the renal veins}

The water, electrolyte, and renal hemodynamic changes produced by inferior vena caval congestion below the renal veins differed from the changes during vena caval congestion including the kidney in one respect, namely, that the effects were considerably more variable. In individual subjects the various functions changed just as markedly as during vena caval congestion including the kidney, but in other instances there were no changes and occasionally increases occurred. As a consequence, the changes were often less significant, although almost always of the type already described.

During the venous congestion, urine flow (Table I) decreased in only 8 of 13 subjects, remained unchanged in three, and increased in two. The mean value decreased, but not significantly. This variability persisted after release of congestion; urine flow rose in six subjects, remained unchanged in four, and decreased further in three. The mean value returned toward, but not to, the control level.

Sodium excretion (Table II) decreased significantly in the second and third periods of congestion. However, a decided fall occurred in only nine subjects, no change in three, and an increase in the remaining subject. The changes in potassium excretion (Table III) were even more variable but there still was a probably significant decrease in excretion during the third period of congestion. Chloride excretion (Table IV) again decreased in a manner similar to sodium excretion. After deflation of the balloon, the excretions of the three electrolytes and water returned to or toward control levels, but significant decreases in chloride excretion and probably significant reductions in sodium excretion persisted through the first postdeflation period.

Renal plasma flow (Table V) decreased definitely in only four of eight subjects and the mean flow rate did not change significantly. However, the magnitude of the decrease in the mean plasma flow ( -25 per cent) was not less than the decrease ( -27 per cent) which occurred when the renal veins were included in the congested area. Only the variability was greater. Glomerular filtration rate (Table VI) decreased slightly in six of eight subjects during the first 10 minutes of congestion, and the decrease was possibly signifi-
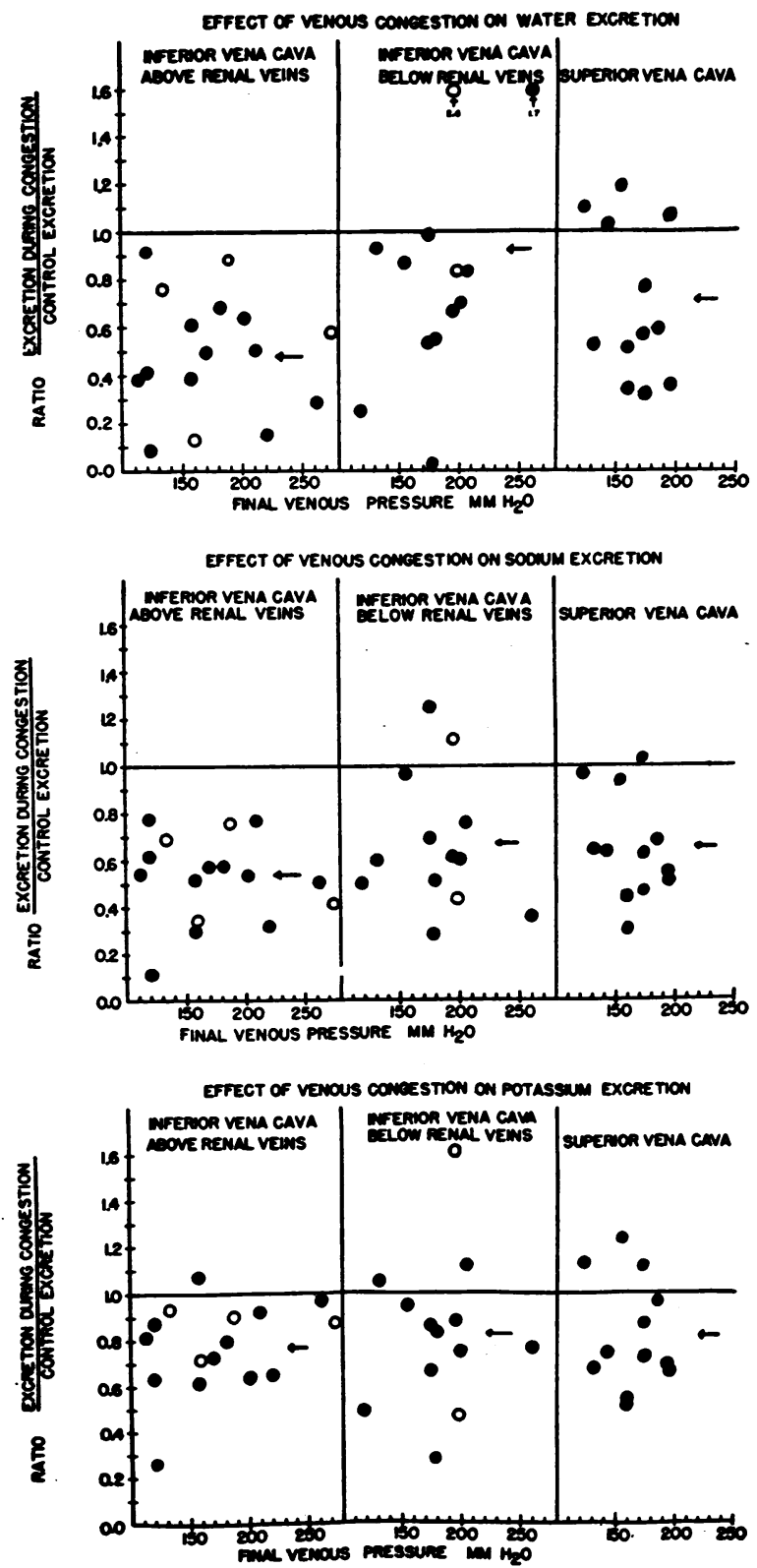

Fig. 4. Relationship between the Decreases in Water, Sodrum, and Potassium Excretions aNd the Degree of Venous Congestion of the Inferior and Superior Venae Cavae

The abscissae indicate the elevated distal venous pressures induced in the three areas. The ordinates indicate the water and electrolyte excretions plotted as a ratio obtained for each subject by dividing the lowest excretion during congestion by the average of the three control excretions.

Each dot indicates one subject, the arrow the average for the respective dots. Solid dots indicate excretions during third period of congestion, open dots during the second congestion period. 
TABLE VII

Effect of venal caval congestion on heart rate (The datai are averaged heart rates per minute per period for number of subjects indicated)

\begin{tabular}{|c|c|c|c|c|c|c|c|c|c|}
\hline \multirow{3}{*}{ 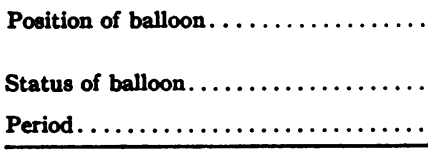 } & \multirow{2}{*}{\multicolumn{3}{|c|}{$\begin{array}{c}\begin{array}{c}\text { Inferior vena cava } \\
\text { above renal veins }\end{array} \\
\text { During inflation }\end{array}$}} & \multirow{2}{*}{\multicolumn{3}{|c|}{$\begin{array}{c}\begin{array}{c}\text { Inferior vena cava } \\
\text { below renal veins }\end{array} \\
\text { During inflation }\end{array}$}} & \multirow{2}{*}{\multicolumn{3}{|c|}{$\begin{array}{c}\text { Superior vena cava } \\
\text { During inflation }\end{array}$}} \\
\hline & & & & & & & & & \\
\hline & 1 & 2 & 3 & 1 & 2 & 3 & 1 & 2 & 3 \\
\hline \multirow{3}{*}{$\begin{array}{l}\text { Number of subjects per } \\
\text { period, N } \\
\text { Mean value per period, } \\
\text { N subjects } \\
\text { Mean control value for } \\
\text { N subjects }\end{array}$} & 11 & 13 & 10 & 13 & 10 & 11 & 11 & 11 & 10 \\
\hline & 74 & 77 & 76 & 75 & 72 & 75 & 80 & 80 & 83 \\
\hline & 73 & 75 & 75 & 72 & 69 & 73 & 80 & 78 & 80 \\
\hline $\mathbf{P}^{*}$ & 0.2 & 0.5 & 0.05 & 0.01 & 0.2 & 0.5 & - & 0.1 & 0.06 \\
\hline
\end{tabular}

* P-Statistical probability per period determined by the method of critical ratio ( $t$ test).

cant. With continued congestion, filtration rate increased in some subjects so that the decrease was no longer significant. After release of congestion both of these renal hemodynamic functions returned quickly to control levels.

In the arterial blood pressures (Table VII), the individual changes were more consistent, and the small falls $(-8$ to $-10 \mathrm{~mm}$. $\mathrm{Hg}$ ) in both systolic pressure and pulse pressure represented significant decreases during the first 10 minutes and probably significant decreases during the remainder of the vena caval congestion. Diastolic and mean arterial pressures, heart rate (Table VIII), and electrocardiogram again remained unchanged. Prompt return to initial values occurred in all pressures upon release of the congestion.

\section{Effects of inflation of the balloon in the su- perior vena cava}

The effects of superior vena caval congestion differed from inferior vena caval congestion in one major respect, water and electrolyte excretions remained significantly decreased after release of congestion. In addition, significant renal hemodynamic changes were absent and small, but significant alterations in arterial blood pressure occurred.

During the venous congestion, water excretion decreased variably but progressively and by the third period was significantly reduced. A fall occurred in 10 of 12 subjects. During the postdeflation measurements, urine flow remained significantly reduced in the first and second periods and possibly even in the third. Sodium excretion fell in all 12 subjects during the venous congestion and the decrease was significant in all three pe- riods. Thirty minutes after release of the congestion, sodium excretion was still significantly decreased. Potassium and chloride excretions were affected similarly.

The mean value for renal plasma flow decreased by 13 per cent during venous congestion (compared with 25 per cent and 27 per cent during congestion of the inferior vena cava) and returned to control levels following deflation of the balloon. The individual changes were variable and almost always small so that no significant change in the group effect occurred. Glomerular filtration rate did not change during or after congestion.

With regard to arterial blood pressure, there was a small ( -6 to $-7 \mathrm{~mm}$. $\mathrm{Hg}$ ) but significant decrease in pulse pressure during all three periods of congestion and probably significant decreases in mean pressure $(-2 \mathrm{~mm} . \mathrm{Hg})$ in the third inflation period and in systolic pressure $(-5 \mathrm{~mm} . \mathrm{Hg})$ in the first inflation period. Diastolic pressure remained unchanged as did the heart rate and electrocardiogram.

\section{Relationship of electrolyte and water excre- tions to the increase in venous pressure}

During congestion of each of the three vena caval areas, the decreases in excretion of sodium, potassium, and water were not related quantitatively to the degree of elevation of venous pressure, up to final venous pressures of $100 \mathrm{~mm}$. to $250 \mathrm{~mm}$. saline (Figure 4). A chance observation suggests that the decreased water and electrolyte excretions were, nevertheless, probably associated with some rise in venous pressure and were not simply due to local alterations in vascular volume. 


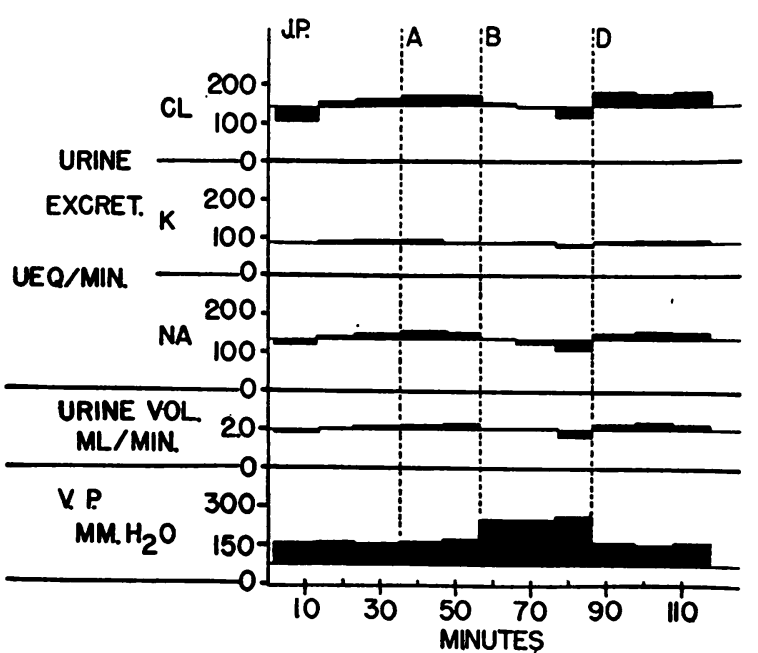

Fig. 5. Water and Electrolyte Excretions DeCREASEd DURING INFLATION OF BALLOON IN THE INFERTOR Vena Cava above the Renal Veins Only When an Increase in Distal Venous Pressure Was Induced

At line $\mathbf{A}$ the balloon was inflated in the vena cava at the level of the mid-hepatic shadow. No rise in femoral venous pressure resulted. At line B the balloon was deflated, positioned at a slightly higher level in the vena cava, and reinflated. The distal venous pressure now rose and electrolyte and water excretions decreased. At line $D$ the balloon was deflated.

For details of plotting see Figure 1.

In subject J. P. (Figure 5) a fully dilated balloon containing $9 \mathrm{ml}$. of diodrast solution was positioned in the inferior vena cava at the level of the midhepatic shadow. The balloon appeared easily of sufficient size to obstruct venous return and congest the vena cava. The distal venous pressure, however, did not rise but remained at $85 \mathrm{~mm}$. of saline. Water and electrolyte excretions did not change. The balloon was deflated, moved upward slightly and reinflated with $8.5 \mathrm{ml}$. of diodrast solution. It now lay at the upper border of the hepatic shadow. Distal venous pressure rose to $175 \mathrm{~mm}$. saline, and water and electrolyte excretions promptly fell.

\section{Relationship of electrolyte and water excre- tions to area congested}

Although qualitatively similar for the three caval areas, the decreases in electrolyte and water excretions were most marked during congestion of the inferior vena cava including the kidneys and less marked during inferior vena caval congestion below the kidneys and during superior vena caval congestion. Thus, mean sodium excretion decreased to 54 per cent of the control value during inferior vena caval congestion including the renal veins, to 67 per cent during inferior vena caval

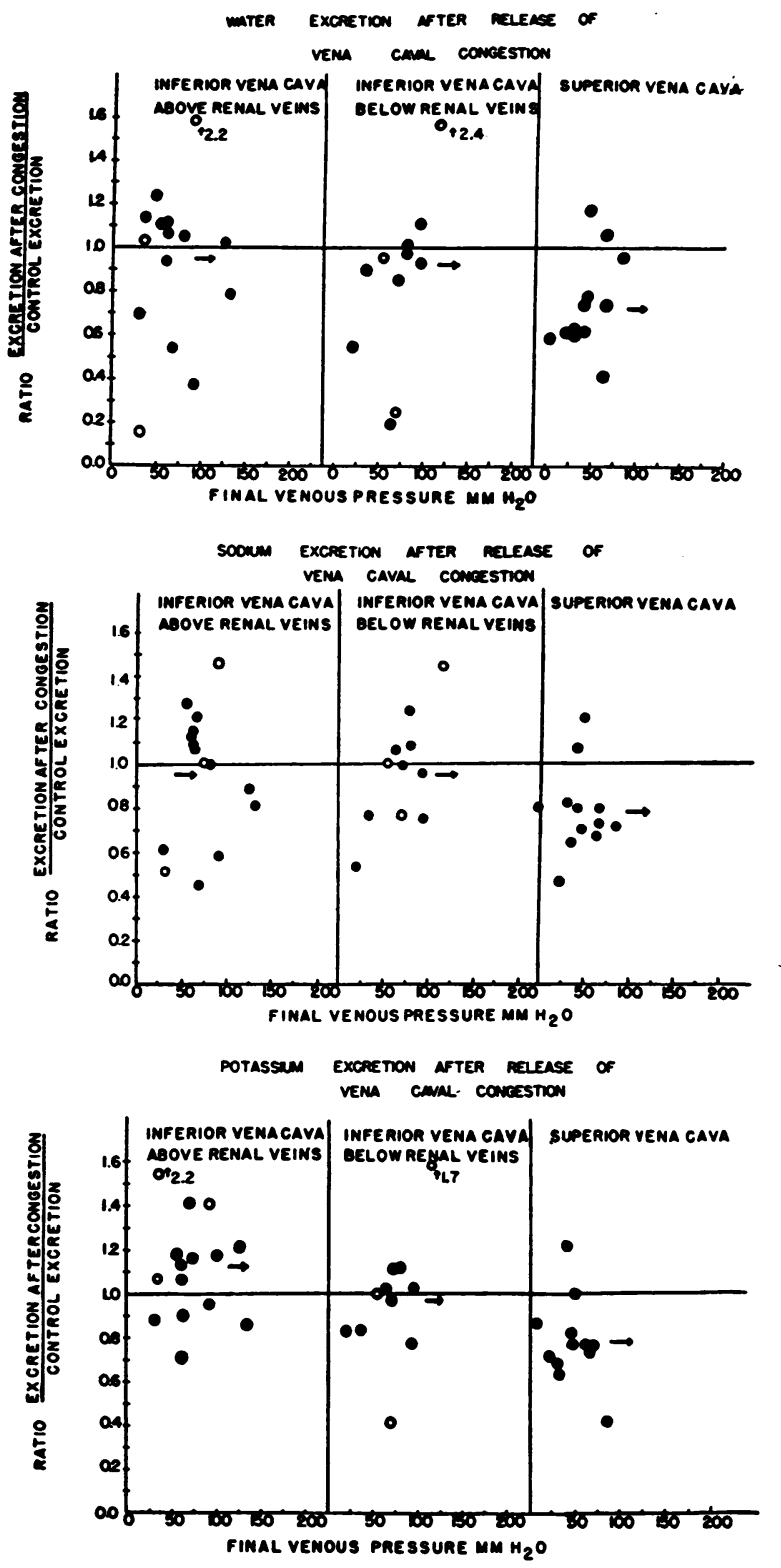

Fig. 6. Urinary Water, Sodium, and Potassium Excretions Following Release of Inferior and Superior Vena Caval Congestion

The abscissae indicate the levels to which the distal venous pressures returned after release of the indicated vena caval congestion.

Plotting of ordinates, dots, and arrows as in Figure 4, except that open dots indicate second post-deflation period and solid dots the third post-deflation period. 
congestion below the renal veins, and to 65 per cent during superior vena caval congestion (Figure 4). During congestion of these three areas, respectively, mean potassium excretion decreased to 76 , 82 , and 81 per cent of control values, and mean water excretion fell to 48,92 , and 71 per cent of initial levels (Figure 4). The effect on chloride excretion was similar to that for sodium. Figure 6 indicates the striking differences in the rates of recovery of the sodium, potassium, and water excretions during the 30 minutes following release of inferior and superior vena caval congestion: essentially complete return to control levels after release of both types of inferior vena caval congestion, virtually no increase above the lowest levels of the congestion period following release of superior vena caval congestion.

\section{DISCUSSION}

No attempt was made to produce a standard degree of hydration or salting of the subjects in these observations. As a result the control levels of water and electrolyte excretions varied markedly among the subjects. Furthermore, in some individuals an undesirable degree of variation occurred in the values for the three control periods, probably due to the difficulty in obtaining reproducible urine volumes in urine collection periods of short duration at low rates of urine flow. The decision was made to accept these variations in order to gain the advantage of observing the effects of vena caval congestion at various spontaneously occurring rates of water and electrolyte excretion. In spite of the variations in the control data the changes induced by vena caval congestion were, when viewed on the whole, quite decisive; the renal excretion of electrolytes and water decreased, and in most respects this effect was similar for both inferior and superior vena caval congestion. The data fail to indicate the mechanisms responsible for these reduced excretions but do permit several interesting considerations.

The decreased excretions of both sodium and chloride were usually associated with a decreased excretion of water for, in most instances, the urinary concentrations of these two electrolytes did not change materially. However, in three subjects there was little or no change in urine flow, and decreases in urinary concentrations accounted almost wholly for the reduced excretion of both so- dium and chloride. With regard to potassium, urinary concentrations usually increased but not sufficiently to compensate for the accompanying reduction in urine flow. Potassium excretion accordingly fell.

Several observations suggest that the decreased electrolyte and water excretions are not related directly to changes in renal hemodynamic functions. In most instances, renal plasma flow and glomerular filtration rate decreased at some time during both inferior and superior vena caval congestion, usually early during the congestion and concomitantly with the initial fall in electrolyte and water excretions. However, as the venous congestion was maintained, both of these renal hemodynamic functions varied considerably. Often they increased and in some subjects even reached control levels during the third period of congestion, while electrolyte and water excretions continued to decrease progressively. Particularly during superior vena caval congestion were the usual decreases in electrolyte excretions encountered without measurable changes in glomerular filtration rate or renal plasma flow. The dissociation between electrolyte excretions and renal hemodynamics was even more marked after release of the venous congestion. Both renal hemodynamic functions returned promptly to their control levels during the first post-deflation period. Electrolyte and water excretions, on the other hand, continued at their low levels or decreased further during the first post-deflation period, increased slowly thereafter and at times had not reached control values in the third period. Furthermore, the prompt return of the renal hemodynamic functions to control levels following release of venous congestion indicates that the delayed recovery of the electrolyte excretions was probably not the result of a lag in the excretion of urine trapped above the bladder.

Although the altered urinary excretions appear not to depend upon decreases in renal plasma flow or glomerular filtration rate, one cannot thereby entirely discount the significance of the observed changes in these renal functions. It is still possible that the early decreases in these functions, in some manner, initiated a sequence of events which then caused the reduced electrolyte and water excretions.

Alterations in intrinsic renal pressures (arterial, glomerular, venous, and tubular) have been 
shown to decrease the excretion of urine by physical mechanisms (18-21). Such mechanisms probably do not play a major role in the decreased electrolyte and water excretions here reported. During inferior vena caval congestion including the renal veins, the mechanisms associated with altered renal venous pressure and, perhaps, altered ureteral and glomerular pressures may have been responsible, in part, for the decreased urinary excretions. However, it is difficult to consider these mechanisms operating during congestion of the superior vena cava or of the inferior vena cava below the renal veins, and it is significant that during congestion of each of the three vena caval areas essentially similar effects were produced. A small change in systemic, hence renal, arterial blood pressure was common to congestion of each of the caval areas. Again, it appears unlikely that these small reductions in arterial pressure were responsible for the reduced electrolyte and water excretions. Certainly the arterial pressure changes were much smaller than the considerable changes in renal arterial pressures which failed to influence electrolyte and water excretions in one series of animal experiments (19). In other animal studies a decided fall (20 mm. $\mathrm{Hg}$ or more) in mean arterial pressure was induced before glomerular filtration and urine flow decreased (22). Furthermore, in several patients, for example R. D., systemic arterial pressure rose during the venous congestion, yet electrolyte and water excretions decreased as usual.

One can conclude, therefore, that the data do not indicate a renal hemodynamic mechanism as the major factor in the decreased electrolyte and water excretions during vena caval congestion. Other renal mechanisms, secondary to primary extra-renal changes, appear to be involved.

Since the vena caval congestion was produced by pooling blood into local areas and thereby altering the distribution of a normal blood volume, hemodynamic changes in the circulatory system, other than in the kidney, could have been induced. The possible participation of such hemodynamic changes in the decreased electrolyte and water excretions merits attention, even though the necessary data on most points were not obtained in this study. Consideration will be given to the following possible changes, each of which has been advocated as capable of influenc- ing renal functions : $a$ ) decreased total blood volume, a consequence of outward transudation of fluid from blood in the congested area ; $b$ ) changes in stretch of vessel walls, including the arteries, arterioles, and capillaries, as well as the veins; c) altered cardiac output, with altered flow in some critical organ, or organs, and consequent changes in their function. With regard to alterations in vascular stretch and in blood flow, the effect of the changes in the non-congested areas, as well as the congested areas, must be considered.

Blood volume probably did not decrease during the vena caval congestion, at least as judged by the absence of changes in plasma protein concentration and in the hematocrit. These findings, plus a similar absence of change in blood electrolyte concentrations, also suggest that the osmotic pressure of blood was not increased. Hence the anti-diuretic response to increased osmolarity of the blood (23) need not be invoked. Fluid transudation from the capillaries probably did occur in the congested areas, but apparently hemoconcentration and a reduction in blood volume were avoided by the return of the transuded fluid into the normal-pressured venous system outside of the congested area.

If the mechanism responsible for the reduced water and electrolyte excretions derives from an altered stretch of vascular walls, the data do not indicate either the vessels involved or the nature of the altered stretch. Two possibilities present themselves. If the initiating mechanism is an increased stretching of blood vessel walls, then all parts of the systemic venous system appear to react similarly, for both superior and inferior vena caval congestion induced the decreased urinary excretions. If decreased stretch is the initiating stimulus, then common to both superior and inferior vena caval congestion might be a decreased stretch of the pulmonary vascular system, an effect considered by some observers (24) to initiate reduced urinary excretions. A choice between the two possibilities, or either one, is not possible.

The failure of the decreases in electrolyte and water excretions to be related directly to the degree of rise in venous pressure does not necessarily exclude the possibility that the decreased excretions were the result of altered vascular stretch. The level to which the venous pressure was raised was purposely limited to a range be- 
tween $100 \mathrm{~mm}$. and $250 \mathrm{~mm}$. of saline, levels comparable to those encountered in congestive heart failure. It is conceivable that within this range all increases in venous pressure may constitute a physiological stimulus (vascular stretch) of the same order of magnitude and hence provoke the same response. The considerably higher venous pressures induced by partial ligation of a renal vein $(3,4)$ or by inflated cuffs about the extremities ( 8 ) may then constitute stimuli of different orders of physiological magnitude and produce varying degrees of reduction in electrolyte and water excretion.

There is the possibility that stimulation of venous walls by a foreign body (the balloon) initiated the urinary effects. Several observations indicate that this is unlikely. The balloon was never inflated to the extent that it wedged in the vena cava and pressed on its walls. In all observations the balloon moved freely in the vascular lumen with respiration and with the transmitted aortic pulse. Furthermore, decreased urinary excretions did not occur when the balloon was inflated once in a subclavian vein and once in an iliac vein where the areas congested were small. Finally, there was the observation (Figure 5) in which full inflation of the balloon failed to induce decreased electrolyte and water excretions when the distal venous pressure did not rise but produced typical reductions when readjustment of the position of the balloon caused a rise in the distal venous pressure.

The mechanism by which altered stretch of vascular walls may affect renal function remains undetermined. Presumably, a neurogenic pathway, involving the sympathetic nervous system, would mediate the stimulus from the vessel wall to the kidney. Data on this point are meager and inconclusive. In some animal experiments urine flow and the excretion of sodium and chloride have been reported to increase acutely following section of the sympathetic nerves to the kidney (25). The experiments do not indicate whether these effects are the result of altered electrolyte transport or of altered hemodynamic function. In contrast are the observations in which electrolyte and water excretion still decreased when venous congestion was produced in sympathectomized (lumbo-dorsal) men by inflating cuffs about the thighs (8).
With respect to altered blood flow as a possible mechanism responsible for the decreased urinary excretions, the data are again meager. A preliminary observation suggests that cardiac output decreases during the venous congestion induced in extremities by inflated cuffs and that the associated reductions in electrolyte and water excretions are prevented, or returned toward control levels, when cardiac output is increased by transfusions (26). However, full data concerning cardiovascular dynamics during venous congestion have not been published. Moreover, it seems unlikely that cardiac output of itself alters the renal excretion of water and electrolytes directly. A more reasonable possibility would be that altered cardiac output induces hemodynamic effects in an organ, or organs, with consequent alteration in their function, which in turn causes the decreased excretions by some renal effect. The hemodynamic alterations in one organ, the kidney, and their significance have been discussed. No data are available concerning the effect of venous congestion in altering the hemodynamics and functions of other organs.

Altered function in an organ would presumably produce renal effects by a humoral mechanism. Although the decreased electrolyte and water excretions were in general related to the period of venous congestion, implying a hemodynamic cause, the participation of a humoral component was suggested by the tendency of the decreased electrolyte and water excretions to outlast the general and renal hemodynamic effects, after venous congestion was released. This effect was particularly evident after superior vena caval congestion, suggesting thereby the participation of a humoral substance, possibly pituitary in origin, in the effects of venous congestion of the head. The participation of such a substance in the effects of inferior vena caval congestion is much less evident. In the present study, the circulation was well maintained during the venous congestion and certainly nothing approaching circulatory collapse, known to produce a release of pituitary anti-diuretic hormone (27), occurred. However, the circulatory changes which did occur were comparable to those observed during quiet standing when pituitary anti-diuresis also occurs (27). Finally, even though the observed fall in water excretion may be consistent with the known 
action of the pituitary anti-diuretic hormone, this hormone is not known to produce the type of decreases in electrolyte excretion encountered in these observations.

This discussion, like this study, has raised many more questions than it has answered. Further observations are required of hemodynamic effects, both cardiac and of individual organs, or hormonal participation, pituitary and adrenal in particular, and of the neurologic component, especially the sympathetic nervous system. Finally, these studies were undertaken in order to obtain information concerning the relationship between venous congestion and edema formation in congestive heart failure. How pertinent the present data are on this point is highly conjectural. The observations dealt only with acute changes. The effects of long-continued, induced venous congestion in man remain to be determined.

\section{SUMMARY}

1. Elevated vena caval pressures, ranging from $100 \mathrm{~mm}$. to $250 \mathrm{~mm}$. saline, were produced for periods of 30 minutes by the inflation of a balloon in the inferior vena cava above the renal veins in 16 subjects, in the inferior vena cava 'below the renal veins in 13 subjects, and in the superior vena cava in 12 subjects.

2. During the venous congestion of each of the three areas essentially similar changes occurred in water and electrolyte excretions, renal hemodynamics and arterial blood pressures:

a) The urinary excretions of sodium and chloride, and less consistently of potassium and water, decreased.

b) Urinary electrolyte concentrations tended to remain unchanged and the reduced electrolyte excretions were usually due to the reduced water excretion. Occasionally water excretion decreased little or not at all, yet electrolyte concentrations fell decidedly.

c) Renal plasma flow and glomerular filtration rate usually decreased by 15 to 25 per cent at the onset of the venous congestion and concomitantly with the reduction in water and electrolyte excretions. As venous congestion was maintained, both renal hemodynamic functions improved and were returning toward control values while water and electrolyte excretions remained at their low levels or decreased further. Filtration fraction did not change.

d) Systemic arterial pressure changed little; systolic pressure and pulse pressure fell slightly (5 to $10 \mathrm{~mm}$. $\mathrm{Hg}$ ), while diastolic pressure and mean pressure remained essentially unchanged. Heart rate and the electrocardiogram remained unaltered.

e) Arterial hematocrit and plasma protein concentration did not change.

3. Following release of inferior vena caval congestion, both including and excluding the kidneys, water and electrolyte excretions, renal plasma flow and glomerular filtration rate returned to, or well toward, control levels, the renal hemodynamic functions promptly, the urinary excretions within 30 minutes.

4. Following release of superior vena caval congestion, water and electrolyte excretions returned toward control levels slowly, or not at all, and were still reduced 30 minutes after release of the congestion. Renal plasma flow and glomerular filtration rate, on the other hand, returned promptly to control values.

5. These observations indicate that acute congestion of a sizable segment of the venous system induces a decreased urinary excretion of water and electrolytes. The mechanisms responsible for this effect remain to be determined.

\section{ACKNOWLEDGMENTS}

The authors wish to thank Dr. J. Deaver Alexander for his assistance in the early phases of this study, Miss Dorothy Connolly and Miss Patrica Smith for technical assistance during the observations, and Miss Dorothy DeLorenzo, Miss Shirilyn Shulman, Mrs. Rae Peterson, and Mrs. Lois Schoenberger for their careful analysis of the many specimens.

\section{REFERENCES}

1. Hwang, W., Akman, L. C., Miller, A. J., Silber, E. N., Stamler, J., and Katz, L. N., Effect of sustained elevation of renal venous pressure on sodium excretion in unanesthetized dog. Am. J. Physiol., 1950, 162, 649.

2. Fishman, A. P., Stamler, J., Katz, L. N., Miller, A. J., Silber, E. N., and Rubenstein, L., Mechanisms of edema formation in chronic experimental pericarditis with effusion. J. Clin. Invest., 1950, 29, 521. 
3. Blake, William D., Wégria, René, Keating, Richard P., and Ward, Henry P., Effect of increased renal venous pressure on renal function. Am. J. Physiol., 1949, 157, 1.

4. Selkurt, Ewald E., Hall, Philip E., and Spencer, M. P., Response of renal blood flow and clearance to graded partial obstruction of the renal vein. Am. J. Physiol., 1949, 157, 40.

5. Schilling, John A., McCoord, Augusta B., Clausen, Samuel W., Troup, Stanley B., and McKee, Frank W., Experimental ascites. Studies of electrolyte balance in dogs with partial and complete occlusion of the portal vein and of the vena cava above and below the liver. J. Clin. Invest., 1952, 31, 702.

6. Epstein, F. H., Goodyer, Allan V. N., Lawrason, F. D., Relman, A. S., Studies of the antidiuresis of quiet standing: the importance of changes in plasma volume and glomerular filtration rate. J. Clin. Invest., 1951, 30, 63.

7. Bradley, S. E., and Bradley, G. P., The effect of increased intra-abdominal pressure on renal function in man. J. Clin. Invest., 1947, 26, 1010.

8. Wilkins, R. W., Culbertson, J. W., Burrows, B. A., Tinsley, C. M., Judson, W. E., and Burnett, C. H., Antidiuresis and renal vasoconstriction following venous congestion of the limbs in normal, hypertensive and splanchnicectomized subjects. J. Clin. Invest., 1949, 28, 819.

9. Viar, W. N., Oliver, B. B., Eisenberg, S., Lombardo, T. A., Willis, K., and Harrison, T. R., The effect of posture and of compression of the neck on excretion of electrolytes and glomerular filtration: further studies. Circulation, 1951, 3, 105.

10. Lusk, J. A., Viar, W. N., and Harrison, T. R., Further studies on the effects of changes in the distribution of extracellular fluid on sodium excretion. Observations following compression of the legs. Circulation, 1952, 6, 911.

11. Eichna, L. W., Farber, S. J., Berger, A. R., Earle, D. P., Rader, B., Pellegrino, E., Albert, R. E., Alexander, J. D., Taube, H., and Youngwirth, S., The interrelationships of the cardiovascular, renal electrolyte effects of intravenous digoxin in congestive heart failure. J. Clin. Invest., 1951, 30, 1250.

12. Farber, S. J., and Eichna, L. W., An intracardiac catheter with inflatable balloon for producing increased venous pressures in the venae cavae of man. J. Clin. Invest., 1953, 32, 1140.

13. Harrison, $H$. E., A modification of the diphenylamine method for determination of inulin. Proc. Soc. Exper. Biol. \& Med., 1942, 49, 111.
14. Alving, A. S., Rubin, J., and Miller, B. F., A direct colorimetric method for the determination of inulin in blood and urine. J. Biol. Chem., 1939, 127, 609.

15. Bratton, A. C., and Marshall, E. K., Jr., A new coupling component for sulfanilamide determination. J. Biol. Chem., 1939, 128, 537.

16. Jeffery, W. H., Note on the Volhard-Harvey method for the estimation of chlorides in urine. J. Lab. \& Clin. Med., 1927-1928, 13, 687.

17. Phillips, R. A., Van Slyke, D. D., Dole, V. P., Emerson, K., Jr., Hamilton, P. B., and Archibald, R. M., Copper sulfate method for measuring specific gravities of whole blood and plasma, rev. ed., N. Y., Josiah Macy, Jr., Foundation, 1945.

18. Winton, F. R., Physical factors involved in the activities of the mammalian kidney. Physiol. Rev., 1937, 17, 408.

19. Selkurt, E. E., Effect of pulse pressure and mean arterial pressure modification on renal hemodynamics and electrolyte and water excretion. Circulation, 1951, 4, 541.

20. Hall, P. W., III, and Selkurt, E. E., Effect of partial graded venous obstruction on electrolyte clearance by the dog's kidney. Am. J. Physiol., 1951, 164, 143.

21. Selkurt, E. E., Brandfonbrener, M., and Geller, H. M., Effects of ureteral pressure increase on renal hemodynamics and the handling of electrolytes and water. Am. J. Physiol., 1952, 170, 61.

22. Thompson, D. D., Barrett, M. J., and Pitts, R. F., Significance of glomerular perfusion in relation to variability of filtration rate. Am. J. Physiol., 1951, 167, 546.

23. Verney, E. B., Absorption and excretion of water; the antidiuretic hormone. Lancet, 1946, 2, 781.

24. Sieker, H. O., Gauer, O. H., and Henry, J. P., The effect of negative pressure breathing on renal function. J. Clin. Invest., 1952, 31, 662.

25. Kaplan, S. A., and Rapoport, S., Urinary excretion of sodium and chloride after splanchnicotomy; effect on the proximal tubule. Am. J. Physiol., 1951, 164, 175.

26. Judson, W. E., Hatcher, J. D., Halperin, M. H., and Wilkins, R. W., Further studies on the antidiuresis and decrease in sodium excretion during venous congestion of the limbs: Its prevention in normal subjects by a large transfusion: Its absence or presence in cardiac patients with or without congestive failure. J. Clin. Invest., 1952, 31, 642.

27. Brun, C., Knudsen, E. O. E., and Raaschou, F., On the cause of post-syncopal oliguria. Acta med. Scandinav., 1945, 122, 486. 